\section{La evocación de la memoria y la identidad a través de la imagen}

Inmaculada Real López *

Resumen: La imagen como recurso para evocar la memoria es el tema de estudio de este artículo donde se aborda la evolución de los modos de representación. La búsqueda de los orígenes sociales y culturales, lo popular y lo ancestral, son los recursos principales que se mantienen a lo largo del tiempo. A través de las ilustraciones se aprecia cómo se ha procedido a representar el dibujo comprometido, los homenajes y, finalmente, la recuperación del pasado.

Palabras clave: Identidad - memoria - nacionalismo - compromiso social - diseño.

[Resúmenes en inglés y portugués en la página 148]

${ }^{(*)}$ Doctora en Historia del Arte. Lectora en la Université de Rouen Normandie. Miembro del Grupo de investigación Interdisciplinaire sur les Aires Culturelles (ERIAC) de la Université de Rouen.

\title{
Introducción
}

En este artículo se aborda el proceso de configuración de la imagen identitaria de Galicia a lo largo del siglo XX, así como las diferentes fases que se han sucedido hasta consolidar el lenguaje simbólico vinculado a la tradición y a la memoria, el cual se ha conseguido tras un periodo de asimilación y de puesta en valor de los principales emblemas procedentes de la historia cultural gallega. El punto de partida se establece con la recuperación de los elementos identificativos del noroeste español, su lengua, su historia, su literatura, que van configurando la base de un nacionalismo gallego, germen del pensamiento político y compromiso social que derivará en la creación de una nueva iconografía de carácter realista. Es decir, frente al idealismo basado en trazos elegantes y decorativos, propio del modernismo y regionalismo de principios de siglo, se pasará a escenas expresionistas, influidas por la vanguardia alemana, donde se representan temas basados en la injusticia social, a veces, en clave humorística.

Con motivo de la Guerra Civil (1936-1939) esta representación de la sociedad gallega que había sido ilustrada en numerosos periódicos, revistas y libros, quedará censurada dado 
el compromiso de denuncia que había abiertamente expresado, en especial, con la figura de Castelao que fue quien impulsó una nueva reflexión de la población. Aunque en la Galicia franquista este tipo de obra queda interrumpida, en el exilio bonaerense se indagaron nuevos caminos que intentaron suplir el vacío de la identidad que había generado la diáspora. El impulso retomado en esta ocasión por Luis Seoane cogiendo el testigo dejado por Castelao, se basará en recuperar la tradición de la que fueron portadores, a través de varios medios de producción artística e iniciativas culturales, en los que verterá una visión nostálgica del pasado, configurándose una nueva identidad gallega en clave de homenajes. La última clave de este proceso identitario surge en el último tercio del siglo XX, con la puesta en marcha del proyecto cultural El Laboratorio de Formas que impulsa la recuperación de la cerámica gallega de Sargadelos. Esta loza de porcelana se convertía en el soporte donde ilustrar la memoria gallega, en la que fundir tradición y modernidad basada en los nuevos avances del diseño industrial, a la vez que se incorporaban los emblemas identificativos de la historia de Galicia extraídas de su historia y su cultura popular.

\section{Los trazos del diseño y la búsqueda de un lenguaje identitario}

La configuración de la imagen identitaria en Galicia está directamente ligada a la recuperación de la lengua gallega, su historia y su tradición que fue impulsada por los precursores del Rexurdimento gallego ${ }^{1}$. Estos intelectuales buscaron poner el valor el esplendor cultural que había sufrido el enmudecimiento, por lo que a partir del siglo XIX reivindicarían su regeneración, que derivó a la reconstrucción de una identidad colectiva y concluyó con el surgimiento de una política nacionalista. Asimismo, fueron los promotores de la institución As Irmandades de Fala ${ }^{2}$ fundada en 1916 que posteriormente derivó a la constitución del Seminario de Estudos Galegos, el cual se encargaba de analizar desde diferentes disciplinas la identidad gallega. Asimismo, hay que destacar al escritor Antón Villar Ponte autor del manifiesto Nacionalismo gallego. Nuestra afirmación regional ${ }^{3}$ donde defendía su ideario cultural y político, la lengua, la cultura gallega, el nacionalismo, la autonomía, la descentralización y el análisis de la marginación en Galicia. Además, identificó la Galicia culta con la popular y reivindicó los derechos políticos del pueblo a través de su noticiario A Nosa Terra, uno de los medios de comunicación más importantes del nacionalismo gallego. Las aspiraciones de As Irmandades da Fala concluyeron con la creación del Partido Galeguista.

Paralelamente, se fue formando la imaginería gallega que se inició con la estética del regionalismo basada en el refinamiento y la idealización, a la vez que se van definiendo los emblemas más característicos. Pues el regionalismo favoreció la exaltación de los elementos más singulares de la tradición y del folklore en la producción de los carteles, los cuales comenzaron a ponerse en auge desde finales del siglo XIX como resultado del surgimiento de la litografía como nuevo medio de producción seriada que permitía la impresión de imágenes de gran formato y la introducción de colores. El estilo más representativo fue el modernismo con el que se anunciaba espectáculos, publicidad o eventos culturales. Así, por ejemplo, en Santiago de Compostela "el lenguaje visual de los carteles responde, preferentemente, a su sentido religioso y peregrino" (Sobrino, 1993, p. 13), a nivel estético 
comparten similitudes con las obras pictóricas de la época. En este sentido hay que destacar la figura de Castelao, autor del cartel para las fiestas patronales de Santiago en 19124, donde el intelectual opta por la representación de un gaitero y por la técnica de la témpera, consiguiendo "un aspecto semejante al de los dibujos y acuarelas coloreadas de temas costumbristas y festivos que realizó en los primeros momentos de su actividad" (Sobrino, 1993, p. 116), por influjo de la estampa japonesa. Mientras, el artista Camilo Díaz Baliño, encargado de realizar el cartel para la celebración de las fiestas de esta misma ciudad en 1924, recurrió a la representación de los orígenes legendarios de Galicia, símbolos y emblemas del mundo medieval.

Aunque en el cartelismo gallego no se puede hablar de una destacada representación en cuanto a su producción, sí que fue relevante su arte gráfico, pues hubo interesantes dibujantes, ilustradores y caricaturistas que protagonizaron el primer tercio del siglo XX en Galicia, como los ya citados Camilo Díaz Baliño y Castelao, junto a Fernández Mazas, Cebreiro, Federico Ribas, Rafael Barros, Manuel Bujados, entre otros. Artistas que remplazaron la imagen modernista de principios de siglo por una realidad social que "junto a la pintura y otras manifestaciones artísticas conformaron la cultura visual de Galicia hasta 1936" (Sobrino, 1993, p. 116).

La obra artística de Castelao está influida por la consagración de su pensamiento político e ideológico ${ }^{5}$, que motivaría el inicio de su faceta como teórico y su militancia en el galleguismo. Tanto en sus dibujos, artículos, conferencias y escritos, se vislumbra la defensa que hacía sobre el nacionalismo, pues se convertía en la vía de expresión. De hecho, Castelao redactó en 1919 Arte e Galeguismo con motivo de su conferencia en la sociedad La Oliva, donde exponía el planteamiento y la necesidad de hacer un arte que tuviese su propia identidad y se identificase con Galicia ${ }^{6}$. La evolución estilística y discursiva de su trayectoria artística se produjo hacia 1916-1917, coincidiendo con su integración en el movimiento nacionalista As Irmandades da Fala, que supone el inicio de nuevo ideario ${ }^{7}$ que influyó tanto en su creación plástica como en su obra literaria, cuya producción comenzaría a desarrollarse a partir de este momento. La obra de Castelao olvida el carácter decorativo e idílico, para empezar a ser más crítico y verídico, representando la realidad y los problemas que en aquel momento asolaban a Galicia.

Castelao se fue desmarcando del modernismo, que aún queda recogido en la portada de su primer libro, Cousas da vida (1926), dentro del estilo artístico predominante entre finales del siglo XIX y principios del XX con un carácter principalmente decorativo de inspiración naturalista; por un tema más realista y social, aunque también conoció el expresionismo gracias a la bolsa de estudios que recibe en 1921 que le permite viajar a Europa.

Asimismo, hay que citar las ilustraciones de las revistas literarias y el diseño gráfico que comenzó a despertar un interés en el primer tercio del siglo XX. De tal manera que, se incorporó en numerosas revistas de la época como Yunque, Nós, Rosel, Céltiga, entre otras, en las que Camilo Díaz Baliño y, en especial, Castelao intentan

Impulsar una nueva estética que viniera a dar señas de identidad a una sociedad en proceso de normalización. Aunque con desigual fortuna, estos dos artistas, impusieron un estilo y abrieron caminos a posteriores intervenciones editoriales en las portadas y en el cartelismo (Acuña, 1990, s.p.). 
Por tanto, ambos representaron el camino de la renovación y se convirtieron en los referentes directos de los artistas que emprendieron el camino de la ilustración gráfica. Como fue el caso de Álvaro Cebreiro que colaboró en la revista Alfar y Mondariz, también citar a Maside, Souto, Manuel Colmeiro, Laxeiro, Manuel Torres, Fernández Mazas, entre otros. Es decir, los iniciadores de la vanguardia histórica gallega, quienes prestaron un gran interés a las corrientes artísticas europeas, a la estética del granito, y temáticamente, a la Galicia popular, a los labradores y a las marisqueras. Se trataba de un arte lleno de identidad, portador del discurso nacionalista gallego de la generación Nós emprendido por Castelao. Pero, además este polifacético galleguista comenzó a demostrar en sus dibujos la capacidad que tenía para representar la fisionomía y los gestos de una forma sobria y sencilla, tal y como se puede apreciar en las ilustraciones que hizo para El barbero municipal, un seminario de lucha anticaciquil. En él se recoge el análisis que hizo de la gente del pueblo gallego de Rianxo, pues

Se sentía solidarizado con sus paisanos de condición humilde (...) había un gran número de marineros y labradores que vivían en la mayor pobreza, sometidos a la autoridad, con frecuencia despótica y abusiva, de unos cuantos funcionarios y representantes del poder central (Baltar, 1979, p. 25).

Castelao encontró en la caricatura la vía para despertar la compasión de estas víctimas como consecuencia de las políticas abusivas y los estados de desigualdad entre los habitantes de una misma región. Además, prestó atención a otros asuntos como la injusticia, el régimen foral, la miseria, así como las costumbres. El mejor exponente de esta nueva iconografía social es el álbum Nós que realizó en 1931 convirtiéndose en la principal obra gráfica de Castelao, donde aborda las problemáticas del mundo rural que identifican a la sociedad gallega, ayudó al redescubrimiento del pueblo y su drama.

Estos dibujos, que en muchas ocasiones son grabados con la técnica de la linoleografía, se publicaron en varios periódicos ${ }^{8}$ y revistas ${ }^{9}$ como Vida Gallega, y contribuyeron a difundir su obra y a que tuviera un reconocimiento popular. Además, consiguió consagrar una imagen de la sociedad gallega que fue símbolo e identidad del nacionalismo gallego, de tal forma que, el discurso reivindicativo y de denuncia que presentaban estas ilustraciones caricaturescas, comulgaban con los ideales políticos que defendía el Partido Galeguista. De hecho, Castelao no solo fue un gran ilustrador del pueblo gallego, sino también un gran defensor de sus derechos, pues su compromiso social derivó a la defensa del pueblo gallego desde el marco político, tras ser elegido diputado del Partido Galeguista en 1931 y renovar su acta en 1936 por el Partido Galeguista integrado en el Frente Popular. Es decir, su arte era la expresión de su pensamiento, ambos se aunaban en base a un mismo planteamiento. Por otra parte, hay que destacar que la faceta caricaturesca de Castelao marcó el punto de partida del humor gráfico gallego y representó la época dorada ${ }^{10}$ de una generación de artistas formada por Fernández Mazas, Manuel Torres y Carlos Maside, cuyos trabajos fueron publicados inicialmente en la revista Vida Gallega. La caricatura, que se define por la exageración de los rasgos haciendo una interpretación expresionista de los personajes, no tiene por qué ser siempre en el calve de humor. Sin embargo, los artistas gallegos consolidaron en el primer tercio del siglo XX una nueva interpretación de la población -a través 
de la crítica y la ironía- que favoreció la consolidación de la identidad y del discurso galleguista en clave social. En el caso de Fernández Mazas con un trazo lineal, puro y expresivo, consiguió representar los rasgos psicosomáticos de las personas con una gran habilidad, además de denunciar las situaciones sociales y de contribuir a configurar la imagen social e identitaria de la población gallega.

Con motivo de la Guerra Civil (1936-1939) se produjo una paralización y una decadencia de estas formas expresión gráfica, pues estuvieron condenadas, censuradas y prohibidas durante el franquismo, al igual que la vanguardia, debido a su compromiso político y social. De modo que, esta obra dedicada al humor gallego sufrió la ruptura de su primera generación emprendida por Castelao y seguida por otros artistas del primer tercio del siglo XX.

\section{La evocación de la memoria desde el exilio: la imagen como soporte}

El exilio gallego quedó principalmente establecido en la Habana, en Nueva York, en México y en Montevideo ${ }^{11}$, siendo esta última ciudad, junto a Buenos Aires, la que reunió el núcleo más representativo de la identidad gallega en la diáspora. Especialmente a Argentina marcharon los artistas que se convirtieron en los verdaderos exponentes del nacionalismo gallego.

Desde este país, Castelao trabajó de manera incesante para conseguir que se mantuviera vivo en el exilio y lo consiguió gracias a la fundación del Consejo de Galicia que estuvo activo hasta el fin de la dictadura franquista en 1975. Además, hay que destacar sus funciones como ministro sin cartera del Gobierno de la República en el exilio, durante la presidencia de José Giral (1946-1947), nombramiento que le permitió viajar en varias ocasiones a París para continuar las gestiones del proyecto galleguista que veía cada vez con mayor imposibilidad de poder llevarlo a cabo, así como su lucha por conseguir la autonomía de Galicia, el restablecimiento de sus instituciones y la recuperación de la identidad gallega en el exilio. Con el fallecimiento de Castelao en 1950 no se produce una ruptura con el nacionalismo gallego, sino que hay una continuidad desde el ámbito cultural encabezado por Luis Seoane gracias a los numerosos proyectos que llevó a cabo para evocar la identidad gallega en el exilio. Además, consiguió mantener vivo el espíritu gracias al apoyo de otros intelectuales gallegos exiliados como Lorenzo Varela, Rafael Dieste, Otero Espasandín, Núñez Búa o Tobío Fernández. El culmen de este compromiso galleguista, y el que mejor define su actuación, fue la puesta en marcha del Laboratorio de Formas junto a Díaz Pardo. De hecho, este último, ceramista, empresario, artista e intelectual, llegó a Buenos Aires en 1955 en busca de los exiliados gallegos y encontró que en América estaba la Galicia desaparecida, portadora de una identidad arraigada en su tierra de origen de la que habían sido silenciados y apartados, pero que representaba la verdadera identidad gallega. También pudo apreciar la desmemoria que se había producido en el noroeste español como consecuencia de las políticas franquistas.

Clara E. Lida explica cómo en el exilio republicano la memoria "se pudo mantener viva y seguir construyéndose a sí misma, con la ambición también de contraponerla a la dictadura. En este sentido, para el exilio, la memoria fue, a la vez, constitutiva y forjadora de la 
identidad" (Lida, 2009, p. 77). La búsqueda de la identidad desde el exilio republicano no fue algo exclusivo de la diáspora gallega, sino que la evocación de los lugares de origen es un recurso frecuente, pues su rememoración les ayudaba a mantener los hilos de continuidad de la tradición de la que eran portadores. Así, por ejemplo, citar que el icono por excelencia de los republicanos fue la figura del Quijote ${ }^{12}$, dado el paralelismo que tuvieron con el personaje en su vagar andante y el afán de lucha por restablecer la justicia social. Asimismo, también señalar el carácter simbólico que adquirió la pintura del Greco, Zurbarán, Goya, Velázquez o el arte ibérico, que fue reinterpretada por numerosos artistas de la diáspora, pues supuso para los exiliados españoles una fuente directa de inspiración. De hecho, Picasso terminó siendo considerado el embajador del arte español porque en sus obras se puede percibir la huella de la herencia española.

Sin embargo, el arte gallego queda lejos de este tipo de lecturas que han sido recurrentes en el patrimonio de la diáspora, pues los artistas no se identificaron con los iconos de lo español, sino que aportaron su propia simbología y lenguaje plástico como resultado de los vínculos identitarios que habían venido forjando años atrás. De tal manera que, la evocación de los lugares de origen, sus personajes y sus tradiciones no se hizo desde una lectura individualizada, sino colectiva y generacional para rescatar la memoria de la sociedad, el patrimonio y la tierra gallega.

El máximo exponente de la configuración iconográfica y memorística de la Galicia exiliada fue Luis Seoane, quien conserva el afán de trabajar por el pueblo gallego, pero ya no desde un carácter artístico-político, sino desde una perspectiva de homenaje ${ }^{13}$. En su obra se aprecia el afán por renovar el arte gallego e incluirlo en las corrientes de vanguardia, haciendo referencia a su enraizamiento cultural e histórico que manifestó a través de su obra plástica ${ }^{14}$ y sus murales, aunque su producción artística estuvo especialmente dedicada a las editoriales e ilustraciones de revistas. Así, por ejemplo, una de las primeras actividades fue la labor de periodista gráfico y promotor de numerosos proyectos que en España no podía llevar a cabo, debido a la censura franquista. Por tanto, desde la diáspora, desarrolló un trabajo dirigido a la colectividad emigrante y exiliada, una labora que consiguió tener el reconocimiento del pueblo argentino que la entrega del galardón Premio Palanza y el nombramiento como miembro numerario de la Academia Nacional de Bellas Artes en 1968.

En su afán por recuperar el movimiento cultural de la Galicia emigrada impulsó en 1938 la fundación de la revista Galicia do Centro Gallego de Buenos Aires, a propuesta de Rodolfo Prada, que desde el principio se planteó como una vía de reencuentro con los orígenes, intentado restaurar y dando continuidad a la anteriormente iniciada en Santiago de Compostela. Además, Luis Seoane puso en marcha en Argentina la fundación de varias editoriales y revistas no por intereses comerciales, sino "para dignificar la cultura gallega, consciente de que los libros también sirven para aquilatar la dignidad de un pueblo» (Xeitos, 2010, p. 230), intentando así dar continuidad a sus proyectos galleguistas y republicanos anteriores a la Guerra Civil.

Una de las primeras editoriales en las que empezó a trabajar Luis Seoane fue EMECE, creada en 1939 por Mariano Medina y Álvaro de las Casas, este último nacionalista gallego. Sus funciones no sólo era supervisar, diseñar libros e ilustrarlos, como ¡Eh los toros! (1942), sino también elaborar carteles de publicidad, como hizo en 1940 para la colección Dorna. Unos años más tarde, en 1947 junto con Arturo Cuadrado funda la editorial Bo- 
tella al Mar, especializada principalmente en la poesía; y creó colecciones como Hórreo, también series para la Editorial Nova como Santiago de Compostela y Pomba, con el objetivo de difundir la cultura gallega.

Luis Seoane adoptó una actitud poco combativa frente a otros españoles en el exilio, predominó una actitud principalmente nostálgica, de idealización y evocación, donde las emociones y los sentimientos se traducen en formas, es el pintor de la memoria que rinde homenajes siempre desde el ámbito popular rescata "arquetipos latentes. Siempre detrás de la huidiza alma colectiva” (Patiño, 2010, p. 410). Se podría decir que, la producción del grabado tiene sus concomitancias en la obra pictórica que Luis Seoane realiza entre finales de los años cuarenta y los cincuenta, marcado por la influencia del muralismo bizantino donde el hieratismo y la intemporalidad que son dos características predominantes, junto al verticalismo y el estatismo que dio lugar a obras como El Jinete (1958) expuesta en el Museo Carlo Maside. Asimismo, también se conserva en esta misma colección el lienzo O meco (1963) donde Seoane hace referencia a una tradición galega y cuyo tema llevó también al grabado ${ }^{15}$. Esta técnica fue la que más trabajó Seoane en la creación plástica e, incluso, introdujo novedades técnicas, pero utilizó numerosos soportes tradicionales ${ }^{16}$ como la piedra y la madera, con lo que obtuvo resultados distintos. Buena parte de esta producción se conserva en muchos de los libros que ilustró de Lorenzo Varela, Rafael Alberti Neruda, Unamuno, entre otros. De entre los grabados que realizó destacamos las imágenes celtas realizadas en madera que representan las primeras esquematizaciones de la prehistoria que tiene un carácter estético considerado como el "subconsciente colectivo" porque representa la imagen de un pueblo. Seoane presenta un imaginario que tiene su continuidad en las formas celtas, para concluir señalando que los gallegos son los herederos de la abstracción ${ }^{17}$. De tal manera que, en su obra plástica se puede apreciar "los procesos de abstracción del arte moderno. Deconstruir el objeto y la figura hasta reducirla a los elementos constitutivos: esqueleto geométrico y color. Un movimiento, el de la abstracción moderna, que va detrás de la verdad existencial" (Patiño, 2010, p. 412).

Asimismo, resulta interesante destacar la publicación que Seoane hizo en 1944 del Homenaje a la Torre de Hércules ${ }^{18}$ por la editorial Nova de Buenos Aires, que fue acompañada con un prólogo de Rafael Dieste. Este álbum de dibujos evocaba los diversos recuerdos que tenía Seoane del mar del Orzán, posteriormente pasó a representarlo en numerosas pinturas, ilustraciones e incluso murales, un imaginario que se convertía en su propia fuente de inspiración. Estas escenas del mar con algunas figuras como principales protagonistas son una evocación directa a Galicia y a su historia, que era presentada con un trazo lineal y sentido poético. A esta obra hay que sumar, la exaltación antropológica que hizo en varios proyectos, especialmente en dos programas de radio: Centro Lucense de Buenos Aires y Galicia emigrante ${ }^{19}$ donde analizaba numerosos aspectos de la tierra lejana para acercarla a sus paisanos. De este último se editó una revista que bajo el mismo nombre se publicaban noticias gallegas, tradiciones, cultura, en diferentes secciones que contó con varios colaboradores. 


\section{El Laboratorio de Formas: iconografía e identidad. El diseño simbólico de Galicia para recuperar la memoria histórica}

El artista Isaac Díaz Pardo empezó a colaborar con la Galicia exiliada antes de su arribo a Argentina en 1955, tras poner en marcha un taller experimental de cerámica en el Castro de Samoedo (Sada, La Coruña), a finales de los años cuarenta para impulsar la recuperación de la cerámica de Sargadelos, un complejo industrial que realizaba loza al estilo inglés y cuya producción había sido paralizada. Su proyecto despertó tanto interés entre los intelectuales gallegos de la diáspora, que le propusieron montar algo semejante allí, en concreto, en la Magdalena, ciudad ubicada a $100 \mathrm{~km}$. de Buenos Aires. La puesta en marcha de la fábrica tuvo lugar en 1957 y en este proyecto se divisó un nuevo panorama para la recuperación tanto de la industria como de la identidad gallega.

Para entonces Luis Seoane y Díaz Pardo habían encontrado intereses comunes por el diseño, la industria y la dinamización cultural, vías que fueron esenciales para recuperar la memoria, la tradición y la cultura popular a través de un proyecto empresarial vinculado al pueblo de Galicia, y una propuesta de restauración de las instituciones desmanteladas durante el franquismo que tendría por nombre el Laboratorio de Formas. Este proyecto cultural se convirtió en un vivero de ideas que buscaba restablecer la memoria histórica, y al que se incorporaron otros intelectuales gallegos como los escritores Xosé Núñez Búa, Eduardo Blanco-Amor y Lorenzo Varela, entre otros. Se podría decir que, la restauración del pasado fue una de las principales líneas de trabajo que asumió este proyecto cultural junto al compromiso social, dos ejes bien definidos que tenían además por objetivo el "resurgimiento de la cultura gallega" (Patiño, 2010, p. 392), además de la reconstrucción de la identidad y del nacionalismo defendido por Castelao.

Asimismo, este nuevo laboratorio de ideas mostró un gran interés en promover el diseño industrial moderno, de hecho, su organización estaba directamente influida de la herencia vanguardista de la Bauhaus que, a través de la Escuela técnica y científica de Ulm, impulsada después de la segunda Guerra Mundial, mantuvo una amplia comunicación con el diseño de América Latina. A partir de los años 50 el racionalismo se puso en auge, abanderado por Max Bill y Maldonado en Ulm, e influyó notablemente en el diseño de Luis Seoane quien ya había entrado en contacto en los años 30 con los postulados de la Bauhaus. Sin embargo, en defensa de lo ornamental, el artista llegó a afirmar, respondiendo a aquellos

Quienes quieren disciplinar su vida, hacer iguales todas las vidas (...). Nosotros aspiramos a una libertad similar, con una limitación, la de recoger de la historia de nuestro pueblo aquellas formas que fueron caracterizándolo a través de la historia. Al hacerlo, tratamos de afirmar una diferenciación cultural que no queremos que se pierda. (...) En la Bauhaus se fundamentaban las nuevas formas para la industria en las establecidas por los artesanos y se insistía en los procesos del arte popular (Seoane, 1970, pp. 120-121).

De tal manera que, la nueva identidad gallega viene siendo impulsada por el Laboratorio de Formas que ha conseguido incorporar a la cerámica de Sargadelos motivos decorativos, que tienen un valor simbólico y proceden de la cultura gallega, pues como afirma Antón 
Patiño "las formas tiene un ADN y una intrahistoria". Éstas adquirieren formas marinas, la voluta, la espiral, el laberinto de Mogor, la rosa de los vientos, la esvástica de Miño, la roseta, el torque celta o los bajorrelieves de las piedras prehistóricas nórdicas que también fascinaron a Castelao, como también las grafías de los petroglifos. Asimismo, se asimilaron y se popularizaron elementos que estaban presentes en el patrimonio arquitectónico gallego dotándoles de una identidad, tal fue el caso del decorado monferico, procedente de los casetones de la bóveda del Monasterio de Monfero del siglo X de la Coruña; el decorado protomarinico, extraído del decorado de las ménsulas de la Iglesia Románica de San Juan de Portomarín; al igual que se recuperaron motivos procedentes de la rejería románica y de las galerías coruñesas, que contribuyeron al resurgimiento de la cultura gallega desde sus orígenes hasta la historia reciente.

Esta nueva iconografía identitaria que surge en el último tercio del siglo XX y que pervive en la actualidad como símbolo de Galicia, se debe al esfuerzo que hicieron los dos intelectuales, Díaz Pardo y Seoane de investigar y crear nuevas formas artísticas a través de la industria cultural, el compromiso y el diseño, pero en base a la tradición. De tal manera que, lo popular, que puede modernizarse "sin abandonar nuestra identidad cultural esencial, con una tradición que es un traspaso de valores que se enriquecen haciéndonos evolucionar" (Seoane, 1970, p. 37). El traslado del Laboratorio de Formas de Argentina a Galicia dio lugar en 1968, donde continúa produciéndose formas y motivos cerámicos que poseen un gran valor artístico. De tal manera que, se ha conseguido restaurar una producción industrial que se puso en marcha hace doscientos años y que se ha convertido en símbolo de la identidad y de la memoria gallega.

\section{Notas}

1. Movimiento de restauración cultural gallego que se considera como punto de partida la publicación Cantares Gallegos de Rosalía de Castro (1863), que ha sido considerada la primera publicación del renacimiento pleno de esta generación de escritores compuesta por Eduardo Pondal, Vicente Turnes o Rosalía de Castro, Manuel Murguía, entre otros. 2. Esta institución que surge a iniciativa del periodista y escritor Antón Villar Ponte, ligado al regionalismo, recuperó el diario A Nosa Terra, al antiguo periódico que estaba ligado al movimiento agrario Solidaridad Gallega. La nueva edición que publicada entre 1916 y 1936 fue un interesante vocero para la lengua gallega y la comunicación del galleguismo. Tras la Guerra Civil este boletín galleguista tendría su continuidad en el exilio bonaerense. 3. Esta publicación se convertirá en el principal referente para el nacionalismo gallego de los años veinte.

4. Castelao iniciaba su trayectoria artística en la Exposición Regional Gallega celebrada en Santiago de Compostela en 1909 donde obtuvo el reconocimiento artístico de su propia tierra con la entrega de la Medalla de Oro. Asimismo, participó en la Exposición Regional Gallega del Centro Gallego de Madrid en 1912, con obras como La siesta en Rianxo, Copleros o el tríptico Una fiesta en la aldea. Este mismo año, Castelao participó en la Exposición Nacional de Bellas Artes con el tríptico Los Ciegos, donde fue premiado con la segunda 
medalla. Y en la en la Exposición Nacional de Bellas Artes que se celebró en el Palacio de Bellas Artes de Madrid en 1915 obtuvo la tercera medalla.

5. Véase Real, I., (2017). La exportación cultural de la identidad y del nacionalismo gallego en el exilio. El exilio en clave latinoamericana: identidades, memorias, itinerarios y políticas. Estudios: Centro de Estudios Avanzados, 38, 31-45.

6. "El arte para mí no ha sido más que un elemento, un recurso, un medio de expresión, y con el lápiz o la pluma sólo he querido ser un intérprete fiel de mi pueblo, de sus dolores y de sus esperanzas. Dibujé siempre en gallego; escribí siempre en gallego; y si sacáis lo que hay de gallego y de humano en mi obra no quedaría nada de ella". Discurso de Castelao reproducido en Díaz Pardo, I., (2004). Galicia hoy y el resto del mundo. Arteixo: La Voz de Galicia, pp. 107-108.

7. A nivel artístico este nuevo movimiento también tendría su propio eco con el grupo Nós, que sería renovado por la generación Os Novos y la vanguardia gallega que adoptó, como punto de partida, la figura de Castelao el cual se convirtió en la referencia de la identidad gallega.

8. Algunos de estos periódicos fueron El Pueblo Gallego, Faro de Vigo, El Noroeste, Galicia y A Nosa Terra. Este último se convirtió en el vocero del galleguismo desde su fundación en 1917 hasta el inicio de la Guerra Civil.

9. Entre estas publicaciones citar: La Esfera, El Sol, La Ilustración Española y Americana, El Gran Bufón o El Liberal. Además, hay que citar el diseño gráfico que hizo para la revista Nós que fue una revista de cultura donde Castelao era el director artístico. Además, ilustró las portadas de revistas como Cristal o Alborada.

10. Véase Caballero, F., (2015). La segunda edad de oro del humor gráfico gallego (19822000). Revista Internacional de Historia de la Comunicación, 1, (4)198-219.

11. La preferencia de los exiliados gallegos por estos destinos se debe, principalmente, a que fueron lugares de corrientes migratorias desde el siglo XIX, donde ya había establecidas incluso colonias de emigrantes gallegos. Este flujo migratorio se intensificó nuevamente tras la Segunda Guerra Mundial, aunque esta vez, ya no por circunstancias políticas como la diáspora republicana, sino por cuestiones económicas.

12. El reconocido personaje caballeresco ha sido muy representado desde el exilio por artistas como Picasso, Vela Zanetti, Rodríguez Luna, Joaquín Peinado, Blasco Ferrer, José García Tella, Josep Renau, entre muchos otros. También ha sido tema de exposición en El último suspiro de Don Quijote, celebrado en el Museo del Parque Cultural de Molinos en 2016. Véase Abellán García, J. L., "Don Quijote como símbolo del exilio" en Alted, A.; Llusía, M., (2003). La cultura del exilio republicano español de 1939. Actas del Congreso internacional celebrado en el marco del Congreso plural: Sesenta años después (pp. 545554). Madrid: UNED (1).

13. Luis Seoane también fue un conocedor del dibujo caricaturesco que, en ocasiones, llegó a trabajar en clave de humor. De hecho, en 1930 pronunció una conferencia en el Centro Republicano de Santiago con el tema Humorismo en la sociedad moderna: Bagaria, Shum.

14. Véase Garrido Moreno, A., (2003). Evolución plástica de Luis Seoane a través de su labor editorial en el exilio argentino. En Alted, A.; Llusía, M., (Eds.), La cultura del exilio... Op.Cit., pp. 65-80. 
15. Luis Seoane elaboró dos álbumes en 1963 de grabados, en madera y a dos colores, titulados El toro júbilo y $O$ meco. El primero se trata de siete ilustraciones de una fiesta castellana y el segundo de doce sobre una leyenda popular gallega.

16. En Argentina Luis Seoane encontró un paralelismo con Galicia en cuanto a la artesanía gráfica. El intelectual llegó a señalar: "Fuimos contemporáneos al nacimiento del diseño industrial, a la Bauhaus, a la renovación de las artes gráficas y a las primeras convulsiones de lo que se hizo llamar Era Mecánica [...] Nos sentíamos formar parte del proceso evolutivo de Europa, pero sintiendo que en Galicia, en su oculto genio nacional, estaban nuestras raíces más profundas". Patiño, A., "Seoane e o...Op.Cit., p. 408.

17. Véase García Martínez, P., (2017). Desertor de un ejército forastero: Seoane y el movimiento para un arte abstracto en Argentina. Revista Hispánica Moderna. University of Pennsylvania Press. 1 (70) 55-76.

18. Publicación destacada por el American Institute of Graph of Graphic Arts y por la Pierpont Morgan Library de Nueva York entre las mejores publicaciones plásticas realizadas entre 1935 y 1945.

19. Las diferentes secciones que abarcó este programa fueron: Arte, emigración, evocaciones, gastronomía, historia, humorismo, literatura, música y danza, teatro, varios.

\section{Referencias bibliográficas:}

Abellán García, J.L., (2003). Don Quijote como símbolo del exilio. En Alted, A.; Llusia, M., (Eds.), La cultura del exilio republicano español de 1939. Actas del Congreso internacional celebrado en el marco del Congreso plural: Sesenta años después (pp. 545-554). Madrid: UNED (1)

Acuña, X.E., (1990). As capas do libro na arte galega (1900-1936). En Folleto de exposición Capas (Sin paginar). Sada (La Coruña): Museo de Arte Contemporáneo Carlos Maside. Axeitos, X. L. (2010). A descoberta de Galicia por Seoane: unha cultura, un pobo. En Villares, R. (Ed.) Emigrante dun país soñado: Luís Seoane entre Galicia e Arxentina, actas do Congreso Internacional Luís Seoane: Galicia-Arxentina, unha dobre ciudadanía (pp. 217-242). Santiago de Compostela: Consello da Cultura Galega.

Baltar Domínguez, R., (1979). Castelao ante la enfermedad y la muerte. Vigo: Artes Gráficas

Caballero, F., (2015). La segunda edad de oro del humor gráfico gallego (1982-2000). Revista Internacional de Historia de la Comunicación, 1 (4) 198-219.

Díaz Pardo, I., (2004). Galicia hoy y el resto del mundo. Arteixo: La Voz de Galicia.

García Martínez, P., (2017). Desertor de un ejército forastero: Seoane y el movimiento para un arte abstracto en Argentina. Revista Hispánica Moderna. University of Pennsylvania Press, 1 (70) 55-76.

Garrido Moreno, A., (2003). Evolución plástica de Luis Seoane a través de su labor editorial en el exilio argentino. En Alted, A.; Llusía, M. (Eds.) La cultura del exilio republicano español de 1939, actas del Congreso Internacional celebrado en el marco del Congreso Plural: sesenta años después (pp. 65-80). Madrid: Universidad Nacional de Educación a Distancia. 
Lida, C. (2009). Memoria y cultura en vilo: paradojas de la identidad en el exilio, Caleidoscopio del exilio. Actores, memoria, identidades. México: El Colegio de México, Centro de Estudios Históricos.

Patiño, A., (2010) Seoane e o Laboratorio de Formas., En Villares, R. (Ed.) Emigrante dun país soñado: Luís Seoane entre Galicia e Arxentina, actas do Congreso Internacional Luís Seoane: Galicia-Arxentina, unha dobre ciudadanía (pp. 389-420). Santiago de Compostela: Consello da Cultura Galega.

Real, I., (2017). La exportación cultural de la identidad y del nacionalismo gallego en el exilio. El exilio en clave latinoamericana: identidades, memorias, itinerarios y políticas. Estudios: Centro de Estudios Avanzados, 38, 31-45.

Real, I., (2018). El Laboratorio de Formas y las políticas de la memoria. Editorial Académica Española.

Seoane, L., (1970). Hacia un diseño que considere las particularidades de cada país. Cadernos do Laboratorio de Formas, 1, 120-121.

Seoane, L., (1963). El Toro Júbilo, prólogo del autor. Osedo-Coruña: Ediciós do Castro.

Seoane, L., (1963) O Meco, prólogo del autor. Osedo-Coruña: Ediciós do Castro.

Sobrino, Ma L., (1993). O cartelismo en Galicia desde as súas orixes hasta 1936. Sada (La Coruña): Ediciós do Castro.

\begin{abstract}
The image as a resource to evoke memory is the subject of study of this article where the evolution of the modes of representation is addressed. The search for social and cultural origins, the popular and the ancestral, are the main resources that are maintained over time. Through the illustrations you can see how one has moved from committed drawing, to homage and, finally, to the recovery of the past.
\end{abstract}

Keywords: Identity - memory - nationalism - social commitment - design.

Resumo: A imagem como recurso para evocar a memória é objeto de estudo deste artigo, onde é abordada a evolução dos modos de representação. A busca por origens sociais e culturais, a popular e a ancestral, são os principais recursos que são mantidos ao longo do tempo. Através das ilustrações você pode ver como se moveu de desenho comprometido, para homenagear e, finalmente, para a recuperação do passado.

Palavras chave: Identidade - memória - nacionalismo - compromisso social - design.

[Las traducciones de los abstracts fueron supervisadas por el autor de cada artículo] 